\title{
A Gender-Transformative Response to COVID-19 in Myanmar
}

\author{
Isabel Lambrecht, Kristi Mahrt, Catherine Ragasa, Michael Wang, Hnin Ei Win, and \\ Khin Zin Win
}

On 27 April, the Myanmar Government published the COVID-19 Economic Relief Plan (CERP) which aims to mitigate COVID-19's impact on the macroeconomic environment and the private sector and to ease the impact on laborers, workers, and households. The CERP action plan should pay explicit attention to gender discrepancies to avoid unintentional harm or aggravating existing gender inequalities. To ensure an effective response and offer scope for lasting gender-transformative change, the following actions are imperative for women's inclusion in the Myanmar Government's COVID-19 relief measures:

- Select appropriate public investment, rural cash-for work, and labor-intensive infrastructure projects based on the extent to which women and girls will benefit from these projects - both as laborers and as end-users.

- Designate women as the recipients of unconditional cash transfers.

- Explicitly target female farmers and entrepreneurs with cash transfers, loan programs, technical assistance, and input provision.

- Organize complementary information campaigns for women, including behavioral change communication on health and nutrition and education on leadership and selfesteem. Campaigns should also promote joint decision-making and denounce domestic violence.

- Institutionalize an effective system to support victims of domestic or gender-based violence.

- Incorporate a gender lens when assessing the impact of the crisis by collecting, generating, and analyzing real-time sex-disaggregated data and statistics.

\section{COVID-19 and gender in Myanmar}

COVID-19, as an economic crisis, hit Myanmar long before the first cases of infections in-country were confirmed. From January 2020 onwards, border closures for people and goods, dwindling supplies of imported raw materials for certain industries, and decreasing demand for services, especially tourism, have strongly affected Myanmar's economy. On 23 March, Myanmar confirmed its first COVID-19 cases and by early April, national and city authorities imposed strict measures to contain the spread of the virus. By 17 May, the country had 182 confirmed cases of COVID-19 infection, with six deaths. 
The COVID-19 Economic Relief Plan (CERP) of the Government of Myanmar comprises seven goals, 10 strategies, 36 action plans, and 76 actions. The goals are to:

1) Improve the macroeconomic environment through monetary stimulus.

2) Ease the impact on the private sector through improvements to the investment, trade, and banking sectors.

3) Ease the impact on laborers and workers.

4) Ease the impact on households.

5) Promote innovative products and platforms.

6) Strengthen health care systems.

7) Increase access to COVID-19 response financing.

Several actions under the CERP are notable when the Relief Plan is examined from a gendersensitive and gender-transformative perspective. These include:

- 2.1.1. The provision of low-cost funds.

- 2.1.7. Support farmers, small agri-processors, seed farmers, and agri-businesses for planting and income retention.

- 2.1.7.(d). Establish rural cash-for-work programs.

- 2.3.3. Prioritize and expedite government spending on ready, high impact public investments.

- 3.1.2.(a). Implement labor-intensive community infrastructure projects for those laid off and for returning migrants.

- 4.1.2. Provide unconditional cash and in-kind transfers.

- Goal 6 on health care system strengthening overall.

These plan components are examined more closely in the last section of this policy note.

Myanmar is making significant efforts to respond to the COVID-19 crisis, both in its attempts to contain the spread of the virus as well as in its plans for economic recovery. On 27 April, the Government of Myanmar launched the first public version of the COVID-19 Economic Relief Plan (CERP). ${ }^{1}$ In this plan, the Government not only focuses on the macroeconomic environment and the recovery of the private sector, but also sets out a plan to ease the economic impact of COVID-19 on laborers, workers, and households. (See text box above.)

Economic shocks, such as the current COVID-19 pandemic, may exacerbate gender inequality both in the short and in the long run. In taking action to mitigate the impact of such shocks, overlooking gender and inclusion issues can exacerbate poverty, vulnerability, and gender inequality. In contrast, applying a gender lens in designing policy measures to mitigate the impacts of COVID-19 will make those measures more appropriate and effective while ensuring that they do not cause unintentional harm or aggravate gender inequalities. Additionally, such an approach can help in harnessing and accelerating changes in social norms towards greater gender equality.

In this note, we explain the anticipated impact of the COVID-19 crisis on gender inequality in Myanmar in both the work and the home environments, and how specific measures in the CERP action plan might serve to foster more gender equality and avoid increasing gender discrepancies.

\section{Employment}

Employment - through wage or salaried employment, own-account work, or enterprises - is an important contributor to women's empowerment. Women's employment opportunities, income, and

\footnotetext{
${ }^{1}$ https://www.moi.gov.mm/moi:eng/?q=news/28/04/2020/id-21511
} 
control over that income are linked to higher female decision-making power and often generate positive outcomes for household welfare ${ }^{2,3}$ An economic downturn due to the impact of COVID-19 and subsequent policy measures aimed to mitigate the adverse effects, such as mobility restrictions and physical distancing, will lead to substantial changes in employment in Myanmar. While some of these might be short-term, other changes might be sustained for longer periods as the economy recovers. Given that men and women have different participation rates in Myanmar's labor force, work in different sectors, earn different salaries, and have different employment arrangements, we are likely to see changing gender gaps in employment. This, in turn, could have a large impact on women's empowerment and household welfare.

\section{Gender impacts through sectoral patterns of unemployment.}

The Myanmar Labor Force Survey shows that 78 percent of men of working age were in the labor force in 2017, whereas only 48 percent of women were. The services, manufacturing, and construction sectors of Myanmar's economy were among the first hit by the crisis, later followed by agriculture. ${ }^{4}$ Men are less likely to work in services and manufacturing (respectively 29 and 9 percent of working men) than are women (respectively 39 and 14 percent of working women). However, men are more likely to work in construction and transport (8 percent of men compared to less than one percent of women). Overall, a similar share of working men and women are employed in what can be considered to be 'COVID-19 sensitive' economic sectors (Diao et al. 2020).

The garment industry is the manufacturing sector which employs the largest share of women. In Hlaing Thar Yar, Myanmar's largest industrial zone, for example, women make up 94 percent of garment factory workers. ${ }^{5}$ Out of the 700,000 workers in the apparel industry, it is estimated that half are at risk of suspension without pay or permanent job loss due to COVID-19 related disruptions to the industry. ${ }^{6}$ Additionally, as housing for women working in factories is dependent on their employment, many women are being evicted as factories close. Measures that assist garment workers, such as those initiated by the European Union (EU), are likely to be among the most costeffective in targeting support to affected women.

The agricultural sector still employs the largest share of workers in Myanmar and is critical to food and nutrition security. The strong linkages between the farm and non-farm sectors are not to be underestimated - any negative impact on the non-farm sector will likely lead to major adverse spillover effects on the agricultural sector. A comprehensive and proactive plan is crucial to incentivize and protect producers and entrepreneurs along the food supply chain. Agriculture is sometimes considered a male-dominated sector, with more than half of working men (52 percent) working in agriculture. Yet, 45 percent of working women also work in agriculture. Hence, successful action under CERP Goal 2.1.7, which is to support farmers, agri-processors, and other agribusinesses, will need to target both male and female workers, farmers, and agri-entrepreneurs. For the low-cost commercial funding that is being offered under CERP, measures should be taken to avoid discrimination towards women in obtaining loans (CERP Goal 2.1.1.d). Simple measures will contribute to ensuring that both men and women feel addressed in the CERP and able to participate in the COVID-19 impact mitigation programs. Such measures include ensuring that both male and

\footnotetext{
${ }^{2}$ Maertens, M. and E. Verhofstadt. 2016. "Horticultural exports, female wage employment and primary school enrolment: Theory and evidence from Senegal." Food Policy 43: 118-131.

${ }^{3}$ Majlesi, K. 2016. "Labor market opportunities and women's decision-making power within households." Journal of Development Economics 119: 34-47.

${ }^{4}$ Diao, X., N. Aung, W.Y. Lwin, P.P Zone, K.M. Nyunt, and J. Thurlow. 2020. Assessing the Impacts of COVID 19 on Myanmar's Economy: A Social Accounting Matrix (SAM) Multiplier Approach. Myanmar Strategy Support Program Working Paper 01. Yangon: International Food Policy Research Institute.

${ }^{5}$ https://www.unescap.org/sites/default/files/DA9-04--Myanmar-country-study--Aye-Lei-Tun.pdf

${ }^{6}$ https://eeas.europa.eu/delegations/myanmar-burma/77355/COVID-19-rapid-response-eu-creates-\%E2\%82\%AC5-million-emergencyfund-myanmar-garment-workers en
} 
female actors and men's and women's voices and pictures are used in a respectful and gendersensitive manner in communication campaigns about COVID-19 and about how rural and urban individuals and households might benefit from Government programs to mitigate its economic impact,.

\section{Gendered impacts of distortions to migration}

Domestic and international migration not only offer employment but also support many households across Myanmar through remittances sent back home. The global crisis has led to major job losses among domestic and international migrant workers, and others have voluntarily quit jobs to return to their hometowns during the crisis. Prior to the COVID-19 crisis, roughly 10 percent of Myanmar's population resided abroad, with women constituting about one-third of international migrants. ${ }^{7}$ In addition to international migration, there is also substantial domestic migration in Myanmar. In 2015, nearly a quarter of households in Myanmar received remittances, either from abroad or domestically. In these households, remittances contributed on average 44 percent of household income. ${ }^{8}$ The sudden absence of remittance income will throw many of these households into poverty. Targeting the employment of returned migrant workers through labor-intensive community infrastructure projects is therefore appropriate (CERP Goal 3.1.2). Additionally, projects should ensure that employment opportunities are appropriate, safe, and accessible for female workers.

Households with migrant members trapped away from home will not benefit from actions targeting the employment of returned migrant workers (CERP Goal 3.1.2). However, these households should be considered as potentially vulnerable households, similar to those targeted for unconditional cash transfers (CERP Goal 4.1.2) and eligible for reduced liability burdens (CERP Goal 4.13). As will be explained, it is recommended that cash transfers be extended to female recipients as much as possible.

\section{Gender differences in informal work}

A large share of the labor force in Myanmar are informal workers; being either informally employed or operating informal micro- and small-scale enterprises. Working women are more likely than men to work in informal employment arrangements; while only one-fifth of working men are under a formal employment arrangement, less than one out of ten working women are. ${ }^{9}$ This puts women at greater risk of being laid off during periods of economic uncertainty. Myanmar is extending unemployment benefits to laborers and workers, with additional benefits to pregnant women (CERP Goal 3.1.1). However, at the national level, relatively few will benefit from these measures given the small share of formally employed workers. Other donors, such as the EU, have started making transfers to compensate laid-off workers from garment factories, mainly women. ${ }^{10}$

Despite efforts to reach laid-off workers from small and medium enterprises, transfers are likely to primarily reach those from the largest enterprises. Micro firms with between one and nine employees comprise 68 percent of the manufacturing enterprise population in Myanmar. ${ }^{11}$ Micro and informal enterprises tend to hire less-skilled employees and to replace them more frequently than do other enterprises. Being informal, these enterprises and their workers might be less able to make use of initiatives to attenuate the impacts of COVID-19 and to face more challenges in accessing

\footnotetext{
${ }^{7}$ Ndegwa, D. 2016. Migrants from Myanmar and risks faced abroad. Geneva: International Organization of Migration (IOM).

${ }^{8}$ Authors' own calculation based on the Myanmar Poverty and Living Conditions Survey (MPLCS 2015).

${ }^{9}$ Ministry of Labour, Immigration and Population, Department of Labour. 2017. Annual Labour Force Survey - 2017. Quarterly Report

(1st Quarter, January-March 2017). Nay Pyi Taw: Ministry of Labour, Immigration and Population.

10 https://eeas.europa.eu/delegations/myanmar-burma/77355/COVID-19-rapid-response-eu-creates-\%E2\%82\%AC5-million-emergencyfund-myanmar-garment-workers en

${ }^{11}$ Central Statistical Organization, Ministry of Planning and Finance and UNU-WIDER, 2018. Myanmar Micro, Small, and Medium Enterprise Survey 2017. Descriptive Report. Nay Pyi Taw: Central Statistical Organization.
} 
credit. Myanmar men, in their roles as household heads, are generally seen as the appropriate persons to deal with government and financial institutions under such circumstances. However, it will be important to ensure that information campaigns regarding low-cost funds for micro-, small-, and medium-scale enterprises (CERP Goal 2.1.1.) particularly encourage and support female entrepreneurs to apply.

Informal traders and entrepreneurs might also be particularly vulnerable when tensions arise around the enforcement of COVID-19 control regulations. These businesses and the environments in which they work might not easily conform to the expectations of cleanliness and hygiene required during public health crises. Cholera outbreaks in some African countries have led to crackdowns of informal markets, resulting in the loss of livelihoods for many vendors, most of whom were women. ${ }^{12}$ COVID-19 lockdowns of food markets in various countries are already causing food shortages and loss of livelihoods. Women, who make up most of the traders in these informal food markets, have been particularly affected. Additionally, investments in sanitation, water, and handwashing facilities in the markets which most poor consumers depend for their food purchases have become more important than ever. Thus, it is imperative that these investments are also considered for the public investments and community infrastructure projects that are implemented in support of CERP goals 2.3.3 and 3.1.2.

\section{At home}

\section{Household chores}

Women in households in Myanmar typically perform a larger share of household chores than do men and are often the primary caretakers of children, elderly, and sick people. In doing so, women often forego opportunities to enter the workforce. A new context may necessitate changing patterns of domestic work. While domestic work is generally done by women, for most household chores there is no taboo for men to do them. With more male household members potentially at home due to temporary or longer-term unemployment, it remains to be seen whether men might take on a bigger role in domestic work. However, such an optimistic scenario may produce few tangible effects unless accompanied by intensive gender awareness campaigns.

While childcare under COVID-19 restrictions has been mentioned as a major issue in other countries due to school closures, so far it has been of lesser concern in Myanmar. The lockdown measures, including closure of schools and daycare centers, were implemented at the start of Myanmar's three-month annual school holiday. Nevertheless, the usual vacation time alternatives for children of working parents may not be feasible either due to self- or government-imposed precautionary measures. Examples of these alternatives are children staying with grandparents or relatives and children joining parents at their workplace. Schools are now set to reopen in July, a month later than the normal start of the school year. ${ }^{13,14}$ This may further affect parents' employment options and impose a disproportionate burden on mothers. It also creates risks that many children will be left unattended while their parents are at work. To avoid women foregoing employment for childcare and to avoid children being left at home unattended, we recommend that the Myanmar Government consider arranging for safe childcare options at school from June onwards.

\footnotetext{
12 Resnick, D. 2019. "The Politics of Crackdowns on Africa's Informal Vendors." Comparative Politics 52 (1): 21-51; https://www.ifpri.org/blog/COVID-19-lockdowns-threaten-africas-vital-informal-urban-food-trade

13 https://www.irrawaddy.com/news/burma/myanmar-reopen-schools-july-COVID-19-challenges.html

${ }^{14}$ Myanmar Ministry of Education, 2020. Myanmar COVID-19 National Response and Recovery Plan for the Education Sector. May 2020-October 2021. Nay Pyi Taw: Ministry of Education.
} 
Changes in household composition, mobility, income, working hours, and other factors may require households to reassess the allocation of household income and shift decision-making power within the household. Studies have shown that earning income and earning a larger relative share of household income contribute to increasing the relative decision-making power of an individual in the household. In contrast to many other countries, women in Myanmar often control the household income and participate to a large extent in any decisions as to how the income is used. However, women's roles in decision-making are reduced when they earn relatively less than their husbands. ${ }^{15}$

Despite their role in household decision-making, women are unlikely to be considered the head of the household. Women have a lesser voice than men in their communities and when dealing with local and national authorities. A study of migrant-sending households in Magway found that the absence of adult men in the household promotes women's decision-making, autonomy, and selfesteem. ${ }^{16}$ Male migrants returning home due to the COVID-19 crisis might expect to resume the customary status of household heads, with the respective decision-making power thereof. To the contrary, many returning women might see their decision-making power significantly reduced if they are no longer able to provide financial support to the household.

The Maternal and Child Cash Transfer (MCCT) program has demonstrated that transferring money to women is a successful approach to increase the share of the household budget under women's control. ${ }^{17}$ The experience of MCCT will be invaluable to successfully attaining CERP Goal 4.1.2. Therefore, it is recommended that women are designated as the recipients for cash transfer benefits targeted to a household. However, where experience has shown that such targeting is problematic, either due to normative or logistic challenges, it may not be the right time to challenge these norms or to build in excessive delays in executing payments. Yet, it is still recommended in those cases to install more flexible arrangements in terms of the designated recipient(s). Accompanying messages should emphasize that benefits, although directed to a woman in the household, are intended for the support of the entire household and are to be used according to jointly-made decisions. ${ }^{18}$

\section{Violence against women and children}

An assessment of COVID-19 impacts on violence against women and children globally paints a grim picture for both their short- and long-term welfare. ${ }^{19}$ Distress due to the COVID-19 related economic downturn and the restrictive measures on mobility and quarantine coupled with increased food insecurity and reduced incomes are likely to aggravate tensions within the home. Prior to COVID-19, Myanmar already had high rates of domestic violence. According to the 2015/16 Myanmar Demographic and Health Survey, nine percent of women aged 15 to 49 years had experienced physical violence in the past 12 months. While experience of spousal violence is much more likely when husbands frequently consume alcohol, spousal violence also occurs in households where

\footnotetext{
${ }^{15}$ Ministry of Health and Sports. 2017. Myanmar Demographic and Health Survey 2015-16. Nay Pyi Taw: Ministry of Health and Sports.

${ }^{16}$ Shwe, W.W., Jampaklay, A., Chamratrithirong, A. and S. Thaweesit. 2019. "Husband's international migration. Decision-making autonomy among left-behind wives in rural area of central Myanmar." Journal of Health Research 34(1): 56-67.

${ }^{17}$ Maffioli, E.M., Field, E., Zaw, T.N., Esu, F. and A. Fertig. 2019. LEGACY Program Randomized Controlled Trial Endline Report. Innovations for Poverty Action and Save the Children.

18 On gender-sensitive social protection, see Hidrobo, M., N. Kumar, T. Palermo, A. Peterman, and S. Roy. 2020. Gender-sensitive social protection. A critical component of the COVID 19 response in low- and middle-income countries. IFPRI Issue Brief. Washington, DC: International Food Policy Research Institute. https://doi.org/10.2499/9780896293793

19 Peterman, A., Potts, A., O'Donnell, M., Thompson, K., Shah, N., Oertelt-Prigione, S., and N. van Gelder (2020). Pandemics and Violence Against Women and Children. CDG Working Paper 528. Washington, DC: Center for Global Development.
} 
husbands do not drink. In Myanmar, hotlines have already reported an increase of domestic violence since the start of the COVID-19 crisis. $^{20}$

This prominent issue is remarkably absent in the CERP, both explicitly and implicitly, although it may fit in Goal 4, which seeks to ease the impact of the pandemic on households, or Goal 6, which seeks to strengthen healthcare systems. With the support of international organizations, social workers in the Department of Social Welfare have been trained on the gender dimensions of COVID-19 and on psycho-social counseling, ${ }^{21}$ while relief agencies are organizing telephone helplines. ${ }^{22}$ We recommend that the government learn from these experiences to institutionalize an effective system to support victims of domestic and gender-based violence.

As much as possible, hotlines should also be set up in different languages to reach as many women across the country as possible. Currently, such hotlines may have limited capacity to offer immediate help where movement is restricted. Nevertheless, such facilities ensure victims are being heard and provide a source of information and feedback to the government on the scale and magnitude of violence against women and children.

Moreover, this is an opportune time to launch community and public awareness campaigns regarding the non-acceptability of gender inequality and gender-based violence. Baseline data from January 2020 on women's empowerment in Myanmar's central Dry Zone show that 81 percent of male and 92 percent of female respondents think that wife beating is acceptable under several circumstances. ${ }^{23}$ People confined at or near their homes may more often watch television, listen to radio, or follow messages on social media. Thus, messages from popular and prominent figures can trigger the necessary attention and ensure better reception of key messages on these issues. Examples are Myanmar's world champion martial artist Aung La N Sang's video message against gender-based violence ${ }^{24}$ or the widely viewed discussions with prominent monk Ashin Nandamalabhivamsa about discrepancies between gender discrimination in Myanmar tradition and the teachings of Buddha. ${ }^{25}$ For those with little access to these internet-based options and those without literacy skills, sending short voice messages may serve as an alternative.

Finally, directing cash transfers to women, as discussed, also provides multiple pathways through which to address gender-based violence. Cash transfers can be organized with accompanying messages on available gender-based violence response services. Messages can also inform women of how cash transfers can help cover the cost of accessing these services or how they can help women fleeing an abusive situation. ${ }^{26}$

\section{Health}

Women have different health needs than men, with an obvious example being their need for healthcare services related to fertility, pregnancy, and childbirth. Past disease outbreaks, such as

\footnotetext{
${ }^{20}$ Myanmar Times (April 1) 'Domestic violence rises in Myanmar during community lockdown'

https://www.mmtimes.com/news/domestic-violence-rises-myanmar-during-community-lockdown.html; and

Action Aid News 'COVID-19 crisis: Myanmar's garment workers at greater risk of domestic violence'

https://actionaid.org/news/2020/COVID-19-crisis-myanmars-garment-workers-greater-risk-domestic-violence

${ }^{21} \mathrm{https}$ ://reliefweb.int/report/myanmar/protecting-rights-and-opportunities-women-and-girls-enmy

22 https://actionaid.org/news/2020/COVID-19-crisis-myanmars-garment-workers-greater-risk-domestic-violence

${ }^{23}$ Ragasa, C., K. Mahrt, Z.W. Aung, and I. Lambrecht. 2020. Gender, Crop Diversification and Nutrition in Irrigation Catchment Areas in the Central Dry Zones in Myanmar: Implications for Agricultural Development Support. IFPRI Discussion Paper (forthcoming).

Washington, DC: International Food Policy Research Institute (IFPRI).

${ }^{24}$ https://www.youtube.com/watch?v=n girEliyBo

${ }^{25} \mathrm{https://www.youtube.com/watch?v=BEVwAGDRJZ4}$

${ }^{26}$ Women's Refugee Commission (WRC), Mercy Corps, and International Rescue Committee (IRC). 2020. Toolkit for optimizing cashbased interventions for protection from gender-based violence. Washington, DC: WRC, Mercy Corps, and IRC.

https://s33660.pcdn.co/wp-content/uploads/2020/04/Mainstreaming-GBV-CBI-Toolkit-Overview.pdf
} 
Ebola, Zika, or SARS, have shown that women's needs were insufficiently addressed. Gender considerations were not strongly considered in the response to those outbreaks. The Ebola virus outbreak between 2014 and 2016 in West Africa, for example, contributed to a dramatic increase in maternal mortality due to the diversion of resources away from reproductive and sexual health towards the emergency response. ${ }^{27}$ Heavily affected communities also experienced an increase of out-of-wedlock pregnancies. ${ }^{28}$

Whereas CERP Goal 6 focuses particularly on increasing capacity to deal with COVID-19 infections, it is imperative that this is implemented in addition to, rather than at the expense of, human, financial, and physical capital already in place to ensure maternal and child health. Women must continue to access care for critical routine maternal and child health services in a safe way, including access to family planning and reproductive health. These critical health services should always be maintained. Drawing away human, physical, or financial resources from these critical health services may be detrimental to the lives of many women and children. In a first response to the COVID-19 virus, the Ministry of Health postponed its child vaccination program. This program should resume as soon as an area is deemed safe.

Anecdotal evidence suggests women in Myanmar try to reduce the risk of COVID-19 contamination by avoiding consultations with medical practitioners and moving away from urban centers. This also means they may not receive necessary antenatal care, assistance during childbirth, or postnatal care. Myanmar already has announced extending unemployment benefits for pregnant women to reduce risks of COVID-19 infection through co-workers during the pandemic (CERP Goal 3.1.1). However, this applies only to the small fraction of working women who are formally employed.

Alternative mobile systems are already being developed to engage with expectant or new mothers, although these might reach only those who are more affluent and well connected through internet. Television public service announcements, radio messaging, and short messaging service via mobile phones can be added as tools for communicating with women. Such tools also can be used to encourage hygiene, health, good diet, and nutrition education, which are now even more important than ever to fight against COVID-19 and other diseases.

\section{Actions under CERP to ensure gender-positive impacts in responding to the COVID-19 crisis in Myanmar}

Finally, we provide some recommendations for how a gender-sensitive and gender-transformative approach can be taken in implementing the CERP action plan.

Under Action 2.1.1, low-cost funds are to be provided to ease the impact of COVID-19 on private sector firms. Likewise, under Action 2.1.7, several avenues will be used to support farmers, small agri-processors, seed farmers, and agri-businesses to maintain their income flows and to enable them to plant their crops in the main 2020 cropping season. These include undertaking communication campaigns on COVID-19, providing cash transfers or loans to smallholder farmers who have lost sales revenue or remittance income so that they can make farm input purchases in time for the monsoon planting, and to providing advice on farm productivity enhancement and market connectivity.

\footnotetext{
27 Sochas, L., A.A. Channon, and S. Nam. 2017. "Counting indirect crisis-related deaths in the context of a low-resilience health system: The case of maternal and neonatal health during the Ebola epidemic in Sierra Leone." Health Policy Planning. 32 (suppl 3): iii32-39.

${ }^{28}$ Bandiera, O., N. Buehren, M. Goldstein, I. Rasul, and A. Smurra. 2019. The Economic Lives of Young Women in the Time of Ebola. Lessons from an Empowerment Program. Policy Research Working Paper 8760. Washington, DC: World Bank.
} 
Looking from a gender perspective at these planned actions in the CERP to provide financial support to households and firms, we encourage government to explicitly target female farmers and entrepreneurs for any cash transfer or loan programs, for any technical assistance, and for any input provision. Engagement of both women's and men's groups in seed multiplication, input supply, food production, and logistics should be promoted. Communication campaigns that announce COVID-19 relief measures must ensure that they address women by including both male and female actors, voices, and images, and particularly encourage and support female entrepreneurs to apply to any programs established under these relief measures.

CERP also has several actions related to local investments. These include establishing rural cash-for-work programs (Action 2.1.7.(d)), prioritizing high-impact public investments (2.3.3), and targeting workers who are laid off or returning migrants to engage in labor-intensive community infrastructure projects (3.1.2.(a)).

When reviewing the public investment portfolio and designing labor-intensive community infrastructure projects, benefits to women and girls in communities in both the short and the long run should be key parameters to guide project prioritization and design. Involvement of women in committees that decide where and which infrastructure projects will take place may help to ensure that this infrastructure will also benefit women and girls in these communities in the long run. Projects should provide potential employment for both men and women and ensure equal pay for equal work. Women's participation as laborers can be encouraged through choice of work activity, flexibility of working hours and project locations, and access to day care. Investments in water and sanitation, especially in food markets, can help protect livelihoods and contain the spread of diseases.

Unconditional cash and in-kind transfers (Action 4.1.2) under CERP offer several avenues for strengthening household economic resilience through enhancing the economic roles that women play. Where possible, women should be the designated recipient for cash and in-kind transfer benefits to households. We recognize, however, that in specific settings where such targeting would be problematic due to social norms, this may not be the right time to challenge these norms. In such situations, it may be better to establish more flexible arrangements in terms of the named recipient(s). Accompanying messages should emphasize that program benefits are for the entire household and should be used according to joint decision-making processes within households. These social support programs also offer opportunities to provide behavioral change communication messages to beneficiaries regarding leadership and self-esteem for women and guidance on improving health and nutrition.

Increased domestic and gender-based violence is a major risk during the COVID-19 crisis. Government agencies should work with partners to organize large-scale public awareness and communication campaigns denouncing violence against women and children. In doing so, they can make use of interventions, such as cash transfer programs, to inform women about assistance options, assist those experiencing violence through hotlines, and set up safe women's shelters throughout the country for those who have no alternative accommodation. This can be done either through information and communication technology means or through face-to-face interactions when feasible and safe.

Given the specific health needs of girls and women, healthcare systems strengthening (CERP Goal 6) efforts have significant potential for reducing gender disparities within communities across Myanmar. While there are a wide range of specific health system interventions that would be beneficial to them, the overriding aim should be to ensure that women and girls can continue to safely access critical and routine maternal and child health services, including access to family planning and reproductive health. 
Underpinning these gender-sensitive efforts to address the economic challenges posed by the COVID-19 crisis will be continuing and increasing effort to assess the impact of the crisis by collecting and analyzing existing and real-time sex-disaggregated data and statistics. Representative data on the population of Myanmar is scarce. Moreover, the dissemination and usage of these data are highly restricted. Government departments can spur more rigorous research by making their data more widely available to analysts so that the departments in turn will subsequently benefit from more relevant, accurate, and timely policy recommendations.

More broadly, in responding to the COVID-19 crisis in Myanmar, leaders should resist the temptation of reaching immediate goals that will come at the expense of the long-term benefits related to improved health for women and children, women's economic empowerment, and greater gender equality.

\section{ABOUT THE AUTHOR(S)}

Isabel Lambrecht is a Research Fellow in the Development Strategy and Governance Division (DSGD) of the International Food Policy Research Institute (IFPRI) and program leader of IFPRI's Myanmar Strategy Support Program, based in Yangon, Myanmar. Kristi Mahrt is a Senior Research Analyst in DSGD of IFPRI, based in Colorado, USA. Catherine Ragasa is a Senior Research Fellow in DSGD of IFPRI, based in Washington, DC. Michael Wang is a Leland International Hunger Fellow in DSGD of IFPRI, based in Yangon. Hnin Ei Win and Khin Zin Win are both Research Analyst in DSGD of IFPRI, based in Yangon.

\section{ACKNOWLEDGMENTS}

This policy note has been prepared at the request of the Myanmar Agricultural Policy Support Activity (MAPSA) and USAID. Comments were elicited from MAPSA team members, USAID, and local and international experts. Industry leaders in Myanmar were remotely interviewed to obtain their insights and concerns about the current risks facing their institutions and their clients. The authors thank all contributors for their time and valuable insights, while taking responsibility for the final content.

INTERNATIONAL FOOD POLICY RESEARCH INSTITUTE

1201 Eye St, NW | Washington, DC 20005 USA T. +1-202-862-5600 | F. +1-202-862-5606 ifpri@cgiar.org www.ifpri.org | www.ifpri.info

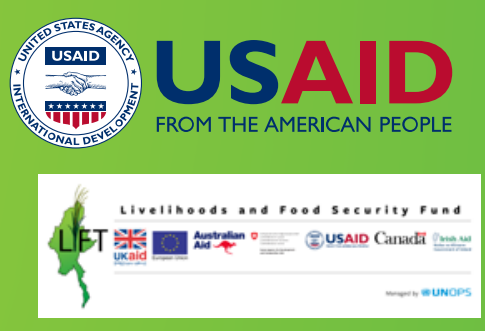

The Myanmar Strategy Support Program (Myanmar SSP) is led by the International Food Policy Research Institute (IFPRI) in partnership with Michigan State University (MSU). Funding support for Myanmar SSP is provided by the CGIAR Research Program on Policies, Institutions, and Markets; the Livelihoods and Food Security Fund (LIFT); and the United States Agency for International Development (USAID). This publication has been prepared as an output of Myanmar SSP. It has not been independently peer reviewed. Any opinions expressed here belong to the author(s) and do not necessarily reflect those of IFPRI, MSU, LIFT, USAID, or CGIAR. 